\title{
Need for establishment of central petrological museums.
}

Sir, - One of the problems facing the petrologists of the world is lack of agreement on the nomenclature of igneous rocks. Many attempts have been made to bring international agreement on nomenclaturs, but these proved to be futile, due to the orthodoxy of some petrologists in adhering to traditional usage. The problem of nomenclature in the case of plants and animals is simpler because of their limited variations under differing environments, which can be denoted quantitatively. On the other hand, rocks of similar mineral composition from different areas show so much variation in character that it is difficult to have a widely accepted terminology. In view of the gradational variations shown by igneous rocks, petrographers are confronted with the difficulty, whether to make a pigeon-hole classification neglecting the gradational variations or to designate the latter by different names without keeping unnatural limitations.

In spite of the above difficulties, there is general agreement amongst petrologists in defining the various rock types based on texture and mineral composition without considering the mode of origin. By following the above two criteria, rocks could be classified conveniently by adopting simpler and more common terms. An attempt in this direction has been made by Albert L. Streckeisen (N.Jb. Miner. Abh. 107, 144-240, $1967)$ in the paper on "Classification and nomenclature of Igneous Rocks" prepared on the basis of the opinions expressed by many of the leading petrologists of the world. In addition to his valuable publication, it would be useful if a permanent committee was set up for petrological nomenclature, which could in turn consider the possibility of developing "Central Petrological Museums" on the lines suggested below.

The centres for such museums could be situated at places where there are the best laboratory facilities and the large collection of rock specimens from different parts of the world. As one centre cannot cater for the needs of all petrographers, opening of three or four centres could be thought of in countries like U.K., U.S.A., U.S.S.R., and India, depending upon the facilities available and the response received from them.

In order to have a complete collection of rocks, an appeal could be made to the different field and research organisations of the various countries for sending a set of typical rock specimens from petrologically important areas. The response might well be encouraging if the parties concerned could get technical advice in return whenever required.

It is also essential to have a standing committe for petrology with a few leading workers in this field as memebers. The Committee could be empowered to take decisions and suggest suitable names for new rocks reported from different localities or give their approval for the name suggested by the worker. The members of the Committee, a few of them stationed at the "Central Petrological Museums", would have access to the typical rocks already mentioned, as it would be easier for them to make a comparative study. In this matter UNESCO can play an important role by taking the initiative in the above direction to establish such centres of Petrological Museums. UNESCO has already stressed the need for active rescarches in geology and international co-operation is sought for this purpose in their programme for 1969-70. If there is help and encouragement from them the above proposals could easily matcrialise.

Further, it may be pointed out that a list of newly discovered rocks, which have been accepted by the committee, could be published in any leading international journal dealing with petrology, as is being done in the case of new minerals reported in Mineralogical Magazine, or American Mineralogist.

School of Studies in Geology

S. Subba Rao

Vikram University

Ujjain (M.P.)

India

January 22nd, 1970 